\title{
PROPRIEDADES FÍSICAS DO SOLO RELACIONADAS A DIFERENTES NÍVEIS DE OFERTA DE FORRAGEM DE CAPIM-ELEFANTE-ANÃO CV. MOTT ${ }^{1}$
}

\author{
ILDEGARDIS BERTOL ${ }^{2}$, JAIME ANTONIO DE ALMEIDA ${ }^{2}$, EDISON XAVIER DE ALMEIDA ${ }^{3}$ e CLAUDINEI KURTZ ${ }^{4}$
}

RESUMO - O excesso de carga animal ocasionado por diferentes lotações sobre as pastagens pode afetar algumas propriedades do solo, aumentar a suscetibilidade à erosão hídrica e diminuir sua capacidade produtiva. A pesquisa, realizada em 1996, na Estação Experimental da EPAGRI, Ituporanga, SC, objetivou avaliar as alterações na densidade do solo, porosidade, diâmetro médio ponderado dos agregados e taxa de infiltração de água no solo submetido a diferentes níveis de oferta de forragem numa pastagem de capim-elefante-anão (Pennisetum purpureum Schum.) cv. Mott. Foram estudados os níveis de oferta de forragem: 4,0, 8,0,12,0 e 16,0\%, além de uma área de campo natural sem pastejo e uma área de mata nativa (testemunha), em Cambissolo álico. Os resultados indicaram uma diminuição da densidade, com conseqüente aumento da porosidade e do diâmetro médio dos agregados com o aumento da oferta de forragem equivalente à diminuição da pressão de pastejo. A taxa inicial de infiltração de água no solo tendeu a diminuir com o aumento da oferta de forragem. Abaixo do nível crítico de $12,0 \%$ de oferta de forragem, as propriedades físicas do solo foram fortemente afetadas pelas altas pressões de pastejo.

Termos para indexação: densidade do solo, taxa de infiltração, estabilidade de agregados, pressão de pastejo.

\section{SOIL PHYSIC PROPERTIES RELATED TO FORAGE OFFER LEVELS OF DWARF ELEPHANT GRASS CV. MOTT}

\begin{abstract}
Animal grazing at different grazing pressures can affect some important soil properties on pastures, increasing soil susceptibility to water erosion and decreasing its productive capacity. The experiment was conducted at EPAGRI Experimental Station, in 1996, Ituporanga, Santa Catarina State, Brazil, with the objectives of evaluating alterations in soil density, porosity, weighed average diameter of aggregates and soil water infiltration rate on dwarf elephant grass (Pennisetum purpureum Schum.) $\mathrm{cv}$. Mott pasture submitted to different forage offer levels. The levels of forage on offer were: 4.0, 8.0, 12.0 and $16.0 \%$, besides a natural pasture treatment without grazing and a native forest area (checkplot), on sandy loam soil (Inceptisol). The results showed a decrease on porosity and weighed average diameter of aggregates for treatments with lower forage on offer. Soil water infiltration rate increased in the lower levels of forage on offer. Below the critical level of forage on offer of $12.0 \%$, soil physical properties were strongly affected by the higher grazing pressure levels.
\end{abstract}

Index terms: soil density, soil water infiltration rate, water aggregates stability, grazing pressure.

\footnotetext{
${ }^{1}$ Aceito para publicação em 15 de junho de 1999. Financiado pela Universidade do Estado de Santa Catarina (UDESC) e Empresa de Pesquisa Agropecuária e Extensão Rural de Santa Catarina (EPAGRI).

${ }^{2}$ Eng. Agrôn., Dr., Dep. de Solos, CAV/UDESC, Av. Luiz de Camões 2090, Caixa Postal 281, CEP 88520-000 Lages, SC. Bolsista do CNPq. E-mail: a2ib@cav.udesc.br

${ }^{3}$ Eng. Agrôn., Dr., Estação Experimental da EPAGRI de Ituporanga, Estrada Geral s/n, Lageado Água Negra, Caixa Postal 98, CEP 88400-000 Ituporanga, SC.

${ }^{4}$ Aluno do Curso de Agronomia, CAV/UDESC. Bolsista do CNPq.
}

\section{INTRODUÇÃO}

$\mathrm{Na}$ região do Alto Vale do Itajaí, em Santa Catarina, predominam as formas de relevo ondulada e fortemente ondulada, com solos de muito baixa fertilidade natural, notadamente Cambissolos de textura argilosa e média. As áreas destinadas à criação de bovinos normalmente são pequenas, e a oferta de forragem natural é insuficiente para a manutenção dos animais, que necessitam suple- 
mentação alimentar. Em razão disso, a pesquisa vem indicando o estabelecimento de pastagens cultivadas como alternativa de alimentação do rebanho. Embora com boa cobertura do solo, a utilização destas pastagens vem sendo feita com lotações inadequadas em relação a sua capacidade de produção e às características dos solos.

As propriedades físicas do solo necessitam ser monitoradas em função da oferta de forragem, expressa pela relação entre a massa de matéria seca de lâmina foliar verde por $100 \mathrm{~kg}$ de peso vivo por hectare e por dia. Variando-se os níveis de oferta de forragem tem-se, portanto, diferentes níveis de pressões de pastejo, em que se avalia a real capacidade de produção animal das pastagens. Assim, pode-se buscar o ponto ótimo de oferta de forragem, no qual é possível maximizar os ganhos por animal e por área, e manter pastagens com boa qualidade. Estudos dessa natureza permitem detectar o nível crítico de oferta de forragem, equivalente a uma pressão de pastejo crítica, acima da qual as propriedades físicas do solo podem sofrer alterações indesejáveis.

A intensidade de desfolhação das pastagens e a pressão de pastejo ocasionadas pelo pisoteio dos animais são distintas nos diferentes níveis de oferta de forragem. Nos menores níveis, a pressão de pastejo é maior, e a desfolhação das pastagens é mais severa, causando maior estresse nas plantas. A desfolhação mais intensa das pastagens caracteriza-se por uma maior remoção da parte aérea, obrigando as plantas a utilizarem as reservas de nutrientes das raízes, paralisando o crescimento do sistema radicular, em favor da recuperação da parte aérea (Taylor, 1981).

O manejo dos animais sobre as pastagens implica modificações nas propriedades físicas do solo, a médio e longo prazos (Alderfer \& Robinson, 1947; Chancellor et al., 1962; Bertol et al., 1998). A pressão aplicada pelo pisoteio dos animais ocasiona alterações na densidade e na porosidade do solo, especialmente nos primeiros 3 a $6 \mathrm{~cm}$ de profundidade (Gradwell, 1960; Chancellor et al., 1962; Gradwell, 1966; Bertol et al., 1998). Ocorrem também modificações na resistência dos agregados e na taxa de infiltração de água no solo (Bertol et al., 1998). Estas alterações podem refletir-se no de- senvolvimento do sistema radicular (Taylor, 1981), e também na produção de massa da parte aérea das pastagens (Federer et al., 1961; Gradwell, 1966). O pastejo indiscriminado, sem um adequado manejo das pastagens, pode provocar, ainda, um empobrecimento do solo (Bertol et al., 1998), provavelmente causado pela erosão hídrica em razão da diminuição da cobertura superficial. Este empobrecimento pode ser aumentado em decorrência da extração de nutrientes pelos animais ao consumirem a forragem, embora parte dela retorne ao solo através dos dejetos, contribuindo para a reciclagem de nutrientes.

Este estudo teve como objetivo avaliar as alterações nas propriedades físicas de um Cambissolo álico cultivado com uma pastagem de capim-elefante-anão, cv. Mott, sob diferentes pressões de pastejo.

\section{MATERIAL E MÉTODOS}

A pesquisa foi conduzida na Estação Experimental da Empresa de Pesquisa Agropecuária e Extensão Rural de Santa Catarina (EPAGRI), no município de Ituporanga, Alto Vale do Itajaí, SC, região cujo clima é classificado como $\mathrm{Cfa}$, com temperatura e precipitação médias anuais de $16^{\circ} \mathrm{C}$ e $1.500 \mathrm{~mm}$, respectivamente. O solo onde se localizou o experimento é um Cambissolo álico, com argila de atividade baixa, horizonte A proeminente e textura argilosa no horizonte B. É desenvolvido de rochas sedimentares pelíticas, notadamente a partir de siltitos e argilitos (Universidade Federal de Santa Maria, 1973), com 30\% de argila, $36 \%$ de areia e $34 \%$ de silte no horizonte A. Originalmente, o solo era álico, apresentando, em média, na profundidade de $0-20 \mathrm{~cm}, 1,3 \mathrm{mg} \mathrm{kg}^{-1}$ de $\mathrm{P}, 95 \mathrm{mg} \mathrm{kg}^{-1}$ de $\mathrm{K}$, 4,2 meq $100 \mathrm{~g} \mathrm{~g}^{-1} \mathrm{de} \mathrm{Ca}+\mathrm{Mg}, 4,9 \%$ de matéria orgânica e $\mathrm{pH}$ em água de 4,0. A área experimental foi calcarizada e corrigida com $\mathrm{P}$ imediatamente antes da instalação do experimento, e, após amostrada, apresentou, na profundidade de $0-20 \mathrm{~cm}$, as seguintes características químicas: $6,2 \mathrm{mg} \mathrm{kg}^{-1}$ de P, $72 \mathrm{mg} \mathrm{kg}^{-1}$ de K, 9,3 meq $100 \mathrm{~g}^{-1} \mathrm{de} \mathrm{Ca}+\mathrm{Mg}$, $3,7 \%$ de matéria orgânica e $\mathrm{pH}$ em água de 5,9. Estudaram-se, em 1996, os tratamentos com 4,0, 8,0, 12,0 e 16,0\% de oferta de forragem de uma pastagem de capim-elefante-anão (Pennisetum purpureum Schum.) cv. Mott em pastejo contínuo desde 1994, equivalentes, respectivamente, a $2.436,1.731,1.616$ e $1.200 \mathrm{~kg} / \mathrm{ha} /$ dia de peso vivo, em média, durante o período experimental, além de um tratamento composto de campo natural mantido sem pastejo 
durante os dois anos de condução do experimento. O tratamento-testemunha era composto de mata nativa situada ao lado do experimento de pastejo. Todos os tratamentos continham duas repetições, totalizando 12 parcelas experimentais (potreiros), com área aproximada de um hectare cada uma. De cada parcela experimental foram coletadas amostras em duas profundidades, em dois pontos localizados ao acaso dentro da parcela, totalizando 48 amostras do solo.

As propriedades físicas: densidade do solo, microporos, macroporos e porosidade total foram obtidas utilizando-se amostras do solo indeformadas, coletadas com anéis de $3 \mathrm{~cm}$ de altura por $8,5 \mathrm{~cm}$ de diâmetro nas profundidades de 0-5 e 5-10 cm, nas posições $1-4 \mathrm{~cm}$ e $6-9 \mathrm{~cm}$ dentro das respectivas profundidades, e determinadas conforme a metodologia descrita por Forsythe (1975). A estabilidade de agregados em água foi determinada por balanceamento a úmido, seguindo a metodologia descrita por Tisdall et al. (1978), nas mesmas profundidades acima referidas; o diâmetro médio ponderado dos agregados (DMP) foi calculado conforme Bavel (1949). A taxa de infiltração de água no solo foi avaliada durante uma hora, utilizando-se cilindros concêntricos com carga variável, conforme metodologia descrita por Forsythe (1975), sendo a curva ajustada segundo o modelo de Philip (1957):

$\mathrm{i}=\mathrm{at}^{\mathrm{b}} \mathrm{b}+\mathrm{C}$, onde:

$\mathrm{i}=$ taxa de infiltração de água no solo estimada, $\mathrm{cm} \mathrm{h}^{-1}$;

$\mathrm{t}=$ tempo, $\mathrm{h}$

$\mathrm{C}=$ taxa de infiltração de água no solo determinada ao final de uma hora de teste (considerada constante), $\mathrm{cm} \mathrm{h}^{-1}$; e $\mathrm{a}$ e $\mathrm{b}=$ parâmetros de ajuste do modelo, adimensionais.

As equações de regressão não-lineares foram obtidas ajustando-se os dados de taxa de infiltração em relação ao tempo pela equação de Philip linearizada:

$\log _{10}(\mathrm{i}-\mathrm{C})=\log _{10} \mathrm{a}+(-\mathrm{b}) \log _{10} \mathrm{t}$.

O carbono orgânico do solo foi obtido pela metodologia de Walkley \& Black, descrita em Black (1965).

Os dados de densidade do solo, macroporosidade, microporosidade, porosidade total determinada e diâmetro médio ponderado dos agregados foram interpretados utilizando-se análise da variância, e comparados pelo teste de Duncan a 5\% de probabilidade; a comparação foi feita sempre entre profundidades de um mesmo tratamento. Regressão não-linear foi utilizada para analisar os dados de densidade do solo, macroporosidade, porosidade total e diâmetro médio ponderado dos agregados dentro de cada profundidade.

\section{RESULTADOS E DISCUSSÃO}

Para possibilitar a confecção das Figs. 1 e 2 e a obtenção das respectivas equações não-lineares, foram atribuídos os valores $20 \%$ e $24 \%$ de oferta de forragem para a variável independente, respectivamente para o campo natural e mata nativa.

A densidade normalmente é alterada pela pressão mecânica exercida sobre o solo (Baver et al., 1972), a qual pode ser influenciada pelo pisoteio animal (Gradwell, 1966; Bertol \& Santos, 1995; Bertol et al., 1998) e, ainda, pela desagregação causada pelo preparo excessivo do solo (Bertol, 1989).

Em todos os tratamentos de oferta de forragem estudados, a densidade foi maior na profundidade de $0-5 \mathrm{~cm}$ do que na de $5-10 \mathrm{~cm}$ (Tabela 1$)$. Isto demonstra que a pressão mecânica exercida pelo pisoteio animal foi suficiente para alterar esta variável na superfície do solo, o que concorda com dados de outros autores (Gradwell, 1960; Chancellor et al., 1962; Gradwell, 1966; Bertol et al., 1998). No campo natural e mata nativa, no entanto, a densidade foi maior na camada de $5-10 \mathrm{~cm}$ do que na de 0-5 cm, por causa da ausência de pressão mecânica pelo pastejo e da expressiva contribuição de material orgânico adicionado ao solo pela vegetação, especialmente pelas raízes no campo natural e pelas folhas e galhos na mata nativa. A macroporosidade e porosidade total apresentaram comportamento inverso ao da densidade, em todos os tratamentos, o que é explicado do mesmo modo que na densidade, com exceção da porosidade total na mata nativa (Tabela 1). Neste tratamento, a porosidade total foi maior na profundidade de $5-10 \mathrm{~cm}$, o que se explica pela maior microporosidade nesta camada em relação à profundidade de $0-5 \mathrm{~cm}$, a qual compensou a menor macroporosidade. A microporosidade nos demais tratamentos e o diâmetro médio ponderado dos agregados não apresentaram variação como nas profundidades estudadas (Tabela 1).

Nas profundidades estudadas, a densidade do solo diminuiu com o aumento da oferta de forragem (Fig. 1), a qual corresponde a uma diminuição na pressão de pastejo. Isto pode ser atribuído à menor pressão mecânica exercida sobre o solo (Chancellor et al., 1962). Este comportamento da densidade concorda com dados obtidos por Gradwell (1960, 1966) e Bertol et al. (1998). O menor valor de densidade foi encontrado no tratamento com mata nativa (Tabela 1 ), na profundidade de $0-5 \mathrm{~cm}$ 
(0,57 $\left.\mathrm{g} \mathrm{cm}^{-3}\right)$, explicado pela grande quantidade de restos vegetais semidecompostos presentes na superfície (liteira), bem como pela total ausência de pressão mecânica exercida sobre o solo neste tratamento. O maior valor $\left(1,43 \mathrm{~g} \mathrm{~cm}^{-3}\right)$ ocorreu no tratamento $8,0 \%$ de oferta de forragem na profundidade de $0-5 \mathrm{~cm}$, provavelmente causado pela maior pressão mecânica exercida pelo pisoteio dos animais.

$\mathrm{Na}$ camada de 0-5 cm, os valores de densidade do solo foram altos (Tabela 1), especialmente nos tratamentos 4,0 e $8,0 \%$ de oferta de forragem, equivalentes às maiores pressões de pastejo, o que confirma dados obtidos por Bertol et al. (1998) em condições de campo nativo. Isto demonstra que elevadas pressões de pastejo podem danificar a estrutura do solo, aumentando a densidade.

O aumento da densidade do solo, causado pela diminuição da oferta de forragem, refletiu-se no diâmetro médio ponderado dos agregados (Fig. 1) e na distribuição de tamanho de poros (Tabela 1).

A qualidade estrutural do solo pode ser avaliada pelo diâmetro médio ponderado dos agregados. Agregados maiores normalmente são de boa qualidade, apresentando boa distribuição de tamanho dos poros. No entanto, solos adensados também podem formar agregados grandes, os quais normalmente apresentam baixo volume de macroporos em relação à porosidade total, comprometendo principalmente o processo de infiltração da água no solo (Baver et al., 1972).

Nas profundidades estudadas, o diâmetro médio ponderado dos agregados aumentou com o aumento da oferta de forragem (Fig. 1). O maior valor foi encontrado na mata nativa, especialmente na pro-

TABELA 1. Valores de densidade do solo (Ds), microporosidade (Mi), macroporosidade (Ma), porosidade total determinada (Ptd), diâmetro médio ponderado de agregados (DMP) e relação entre macroporos e porosidade total determinada (Ma/Ptd), em duas profundidades (Prof) do Cambissolo álico submetido a diferentes níveis de oferta de forragem (OF) com capim-elefante-anão cv. Mott (média de duas repetições) ${ }^{1}$.

\begin{tabular}{|c|c|c|c|c|c|c|c|}
\hline Prof & $\mathrm{OF}^{2}$ & Ds & $\mathrm{Mi}$ & $\mathrm{Ma}$ & Ptd & DMP & $\mathrm{Ma} / \mathrm{Ptd}$ \\
\hline$(\mathrm{cm})$ & $(\%)$ & $\left(\mathrm{g} \mathrm{cm}^{-3}\right)$ & ----------- & --- $(\%)$ & ---------- & $(\mathrm{cm})$ & $\left(\mathrm{Ad}^{3}\right)$ \\
\hline $0-5$ & 4,0 & $1,41 \mathrm{a}$ & $34,3 \mathrm{a}$ & $6,4 b$ & $40,7 b$ & $4,2 \mathrm{a}$ & 0,16 \\
\hline $5-10$ & 4,0 & $1,35 \mathrm{~b}$ & $36,7 \mathrm{a}$ & $8,6 a$ & $45,3 a$ & $3,7 \mathrm{a}$ & 0,19 \\
\hline $0-5$ & 8,0 & $1,43 \mathrm{a}$ & $39,6 \mathrm{a}$ & $3,7 b$ & $43,4 b$ & $4,3 \mathrm{a}$ & 0,09 \\
\hline $5-10$ & 8,0 & $1,24 b$ & $39,4 a$ & $7,3 \mathrm{a}$ & $46,7 \mathrm{a}$ & $5,1 \mathrm{a}$ & 0,16 \\
\hline $0-5$ & 12,0 & $1,34 \mathrm{a}$ & $39,3 a$ & $7,1 \mathrm{~b}$ & $46,4 \mathrm{~b}$ & $5,0 \mathrm{a}$ & 0,15 \\
\hline $5-10$ & 12,0 & $1,25 \mathrm{~b}$ & $37,1 \mathrm{a}$ & $10,9 a$ & $48,5 \mathrm{a}$ & $4,3 \mathrm{a}$ & 0,22 \\
\hline $0-5$ & 16,0 & $1,31 \mathrm{a}$ & $39,3 a$ & $7,8 \mathrm{~b}$ & $47,1 \mathrm{~b}$ & $5,0 \mathrm{a}$ & 0,17 \\
\hline $5-10$ & 16,0 & $1,10 \mathrm{~b}$ & $37,7 \mathrm{a}$ & $13,3 \mathrm{a}$ & $51,1 \mathrm{a}$ & $4,8 \mathrm{a}$ & 0,26 \\
\hline $0-5$ & $\mathrm{Cn}$ & $1,10 \mathrm{~b}$ & $35,2 \mathrm{a}$ & $17,0 \mathrm{a}$ & $52,2 \mathrm{a}$ & $4,0 \mathrm{a}$ & 0,33 \\
\hline $5-10$ & $\mathrm{Cn}$ & $1,23 \mathrm{a}$ & $37,8 \mathrm{a}$ & $11,5 b$ & $49,3 b$ & $4,4 \mathrm{a}$ & 0,23 \\
\hline $0-5$ & $\mathrm{Mn}$ & $0,57 \mathrm{~b}$ & $33,2 b$ & $19,8 \mathrm{a}$ & $53,0 \mathrm{~b}$ & $5,5 \mathrm{a}$ & 0,37 \\
\hline $5-10$ & $\mathrm{Mn}$ & $0,82 \mathrm{a}$ & $42,4 \mathrm{a}$ & $15,9 b$ & $58,3 \mathrm{a}$ & $5,0 \mathrm{a}$ & 0,27 \\
\hline $\begin{array}{l}\text { Fonte de } \\
\text { variação }\end{array}$ & GL & & & $-(P>F)$ & & -------- & \\
\hline $\mathrm{OF}$ & 5 & 0,000 & 0,147 & 0,000 & 0,001 & 0,080 & \\
\hline Prof & 1 & 0,180 & 0,010 & 0,177 & 0,001 & 0,354 & \\
\hline OF*Prof & 5 & 0,002 & 0,003 & 0,009 & 0,021 & 0,112 & \\
\hline CV (\%) & & 3,88 & 3,03 & 13,83 & 2,41 & 7,57 & \\
\hline
\end{tabular}

${ }^{1}$ Médias seguidas da mesma letra não diferem entre si pelo teste de Duncan a $5 \%$ de probabilidade.

2 Cn: campo natural; Mn: mata nativa;

${ }^{3}$ Adimensional (representa a relação entre as porcentagens de macroporos e porosidade total determinada). 
fundidade de $0-5 \mathrm{~cm}$, o que pode ser explicado pelo maior conteúdo de carbono orgânico nesse tratamento (Tabela 2), especialmente na camada superficial do solo.

O volume de macroporos é expressivamente diminuído quando aumenta o adensamento causado pela pressão mecânica exercida sobre o solo, refletindo-se num aumento menos acentuado do volume de microporos e numa diminuição também pouco expressiva do volume total de poros (Baver et al., 1972). Assim, em termos de porosidade, os macroporos são os primeiros e mais intensamente afetados pela pressão mecânica exercida sobre o solo.

Nas profundidades do solo estudadas, a porcentagem de macroporos aumentou com o aumento da oferta de forragem (Fig. 2), concordando com dados obtidos por Gradwell $(1960,1966)$ e Bertol et al. (1998). O maior volume de macroporos $(19,8 \%)$ foi encontrado na mata nativa (Tabela 1$)$, na profundidade de $0-5 \mathrm{~cm}$, explicado pela grande

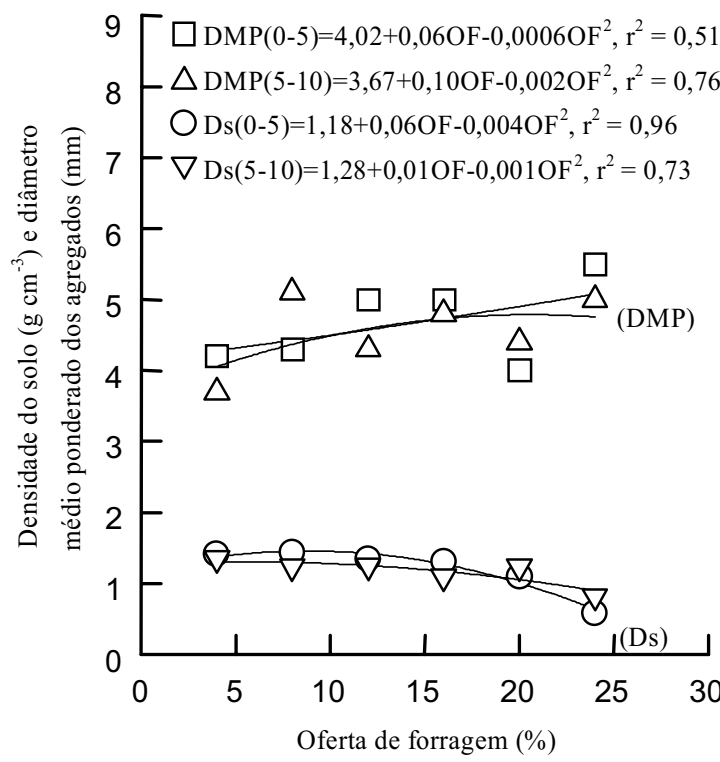

FIG. 1. Relação da oferta de forragem (OF) com a densidade do solo (Ds) e com o diâmetro médio ponderado dos agregados (DMP) em duas profundidades de um Cambissolo álico submetido a pastejo com capim-elefante-anão cv. Mott. quantidade de restos vegetais constituídos de peças relativamente grandes, semidecompostas, depositadas na superfície do solo e, ainda, pela total ausência de pressão mecânica exercida sobre o solo. O menor valor $(3,7 \%)$ ocorreu no tratamento $8,0 \%$ de oferta de forragem, na profundidade de $0-5 \mathrm{~cm}$, indicando que esta variável é fortemente afetada pela pressão exercida sobre o solo pelo pisoteio animal.

A porosidade total aumentou com o aumento da oferta de forragem (Fig. 2), acompanhando o comportamento da macroporosidade. Isto está relacionado com a diminuição da pressão mecânica ocasionada pela menor pressão de pastejo, bem como pelo aumento da oferta de material orgânico causado pelas raízes da cultura nos tratamentos de maior oferta de forragem. No campo natural, as raízes da pastagem ocasionam grande número de macroporos ao serem decompostas, influenciando na macroporosidade e na porosidade total, e, conseqüentemente, na densidade do solo, especialmente na camada superficial. Na mata nativa, a grande quantidade de material orgânico depositado na superfície do solo pela derrama natural da floresta contribui para o aumento da porosidade, com conseqüen-

TABELA 2. Valores de umidade gravimétrica (Ug), umidade volumétrica (Uv) e carbono orgânico (CO) em duas profundidade (Prof) do Cambissolo álico submetido a diferentes níveis de oferta de forragem (OF) com capim-elefante-anão cv. Mott.

\begin{tabular}{lcccc}
\hline Prof & $\mathrm{OF}^{1}$ & $\mathrm{Ug}$ & $\mathrm{Uv}$ & $\mathrm{CO}$ \\
\hline$(\mathrm{cm})$ & $(\%)$ & $-----------(\%)$ & ---------- \\
$0-5$ & 4,0 & 16,5 & 23,0 & 3,0 \\
$5-10$ & 4,0 & 24,1 & 31,2 & 2,7 \\
$0-5$ & 8,0 & 23,4 & 33,3 & 3,3 \\
$5-10$ & 8,0 & 25,4 & 31,4 & 3,2 \\
$0-5$ & 12,0 & 25,5 & 30,1 & 2,6 \\
$5-10$ & 12,0 & 30,1 & 31,9 & 2,9 \\
$0-5$ & 16,0 & 24,8 & 33,0 & 3,0 \\
$5-10$ & 16,0 & 26,1 & 29,4 & 2,2 \\
$0-5$ & $\mathrm{Cn}$ & 17,8 & 21,9 & 3,2 \\
$5-10$ & $\mathrm{Cn}$ & 25,0 & 31,5 & 3,0 \\
$0-5$ & $\mathrm{Mn}$ & 38,3 & 20,0 & 2,8 \\
$5-10$ & $\mathrm{Mn}$ & 32,4 & 26,8 & 2,9 \\
\hline
\end{tabular}

${ }^{1} \mathrm{Cn}$ : campo natural; Mn: mata nativa. 
te diminuição da densidade (Bertol \& Santos, 1995). O maior valor de porosidade total ocorreu na mata nativa (Tabela 1 ), com $58,3 \%$ na profundidade de $5-10 \mathrm{~cm}$, e o menor valor, no tratamento $4,0 \%$ de oferta de forragem, com $40,7 \%$ na camada de $0-5 \mathrm{~cm}$.

A distribuição do tamanho dos poros pode fornecer subsídios tanto sobre a capacidade de drenagem e armazenagem de água, quanto sobre a taxa de difusão de oxigênio e calor no solo. Idealmente, essa distribuição deve situar-se em torno de $33 \%$ de macroporos em relação à porosidade total (Forsythe, 1975).

Todos os tratamentos estudados, com exceção do campo natural e mata nativa na profundidade de 0-5 cm, apresentaram uma distribuição de tamanho de poros menor do que a considerada ideal (Tabela 1). Nas ofertas de forragem de 4,0 e 8,0\%, a porcentagem de macroporos foi da ordem $17 \mathrm{e}$ $12 \%$, respectivamente, em relação à porosidade total, considerando-se a média das duas profundidades estudadas. Isto é explicado principalmente pelos baixos valores de macroporosidade, em razão das maiores pressões de pastejo, o que indica possíveis problemas, principalmente quanto à infiltração da água nesses tratamentos. Nas ofertas de forragem de 12,0 e $16,0 \%$, a porcentagem de macroporos foi da ordem de 18 e $21 \%$, respectivamente, em relação à porosidade total, na média das duas profundidades estudadas (Tabela 1). Isto é explicado principalmente pela porosidade total relativamente alta, o que mostra uma condição mais favorável, especialmente em relação ao movimento da água no solo. Na mata nativa, os macroporos representavam cerca de $32 \%$ da porosidade total, na média das duas profundidades, o que indica uma condição altamente favorável à drenagem da água no perfil do solo, à armazenagem da água a baixa energia para as plantas, e à circulação do ar. Na pastagem natural, os $28 \%$ de macroporos em relação à porosidade total indicam também uma boa condição de distribuição de poros.

O adensamento do solo é uma conseqüência inevitável da diminuição da oferta de forragem, em razão da maior carga animal. Assim, pode-se estabelecer um nível crítico de oferta de forragem quando a carga animal causa algum prejuízo às proprie- dades físicas do solo. Analisando conjuntamente os valores de densidade, diâmetro médio ponderado dos agregados, macroporosidade, microporosidade e porosidade total (Tabela 1 e Figs. 1 e 2), pode-se considerar que os níveis de oferta de forragem abaixo de $12,0 \%$ causam forte alteração negativa nas propriedades físicas do solo. Isto possivelmente afetará a produtividade da pastagem e o ganho animal, a médio e longo prazos.

A taxa de infiltração de água é o melhor parâmetro para se avaliar a qualidade estrutural do solo. Ela reflete o efeito de todas as propriedades do solo que influem combinadamente sobre a infiltração da água, que é controlada pela propriedade com maior grau de limitação (Baver et al., 1972; Forsythe, 1975). A metodologia utilizada para avaliar a taxa de infiltração de água no presente estudo (anéis concêntricos com carga variável), superestima os valores em cerca de dez vezes (Forsythe, 1975), em face do efeito da carga hidráulica sobre

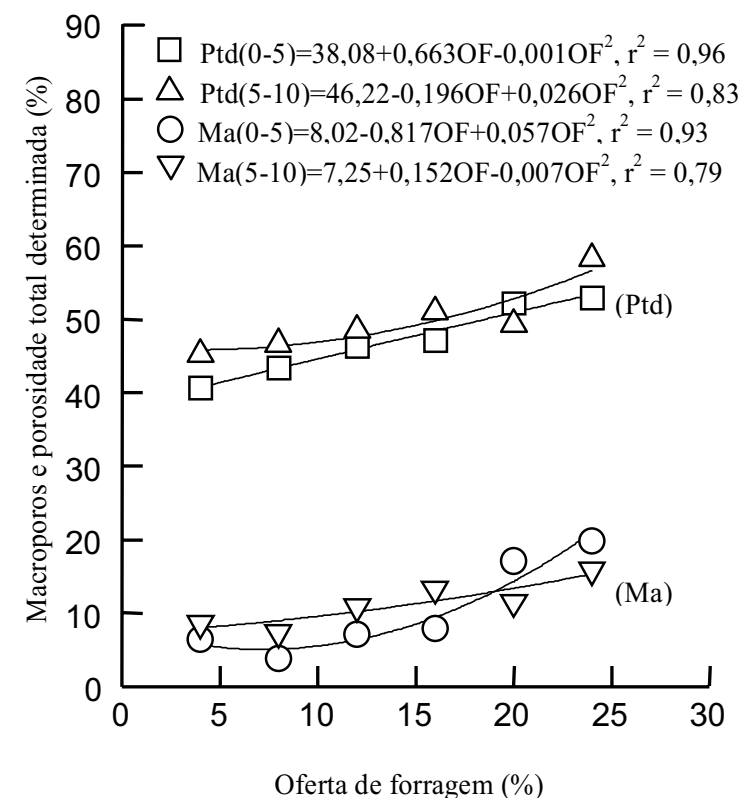

FIG. 2. Relação da oferta de forragem (OF) com a macroporosidade (Ma) e com a porosidade total determinada (Ptd) em duas profundidades de um Cambissolo álico submetido a pastejo com capim-elefante-anão cv. Mott. 
o solo. Portanto, os valores constantes da Fig. 3 devem ser divididos por dez para obter-se a atual taxa de infiltração de água no solo.

Em todos os tratamentos estudados, a taxa de infiltração de água no solo diminuiu com o aumento do tempo de duração do teste de infiltração (Fig. 3). A maior diminuição (87\%) ocorreu no tratamento com $4,0 \%$ de oferta de forragem, equivalente à maior pressão de pastejo, provavelmente explicada pela baixa umidade na profundidade de 0-5 cm (Tabela 2), a qual criou condições para uma alta taxa inicial de infiltração de água no solo $\left(47 \mathrm{~cm} \mathrm{~h}^{-1}\right)$. A menor diminuição na taxa de infiltração de água (78\%) ocorreu no tratamento com $16,0 \%$ de oferta de forragem, equivalente à menor pressão de pastejo, provavelmente pela elevada umidade do solo na profundidade de $0-5 \mathrm{~cm}$, condicionando uma baixa taxa inicial de infiltração de água $\left(9 \mathrm{~cm} \mathrm{~h}^{-1}\right)$.

Todos os tratamentos de oferta de forragem estudados apresentaram valores muito baixos de taxa

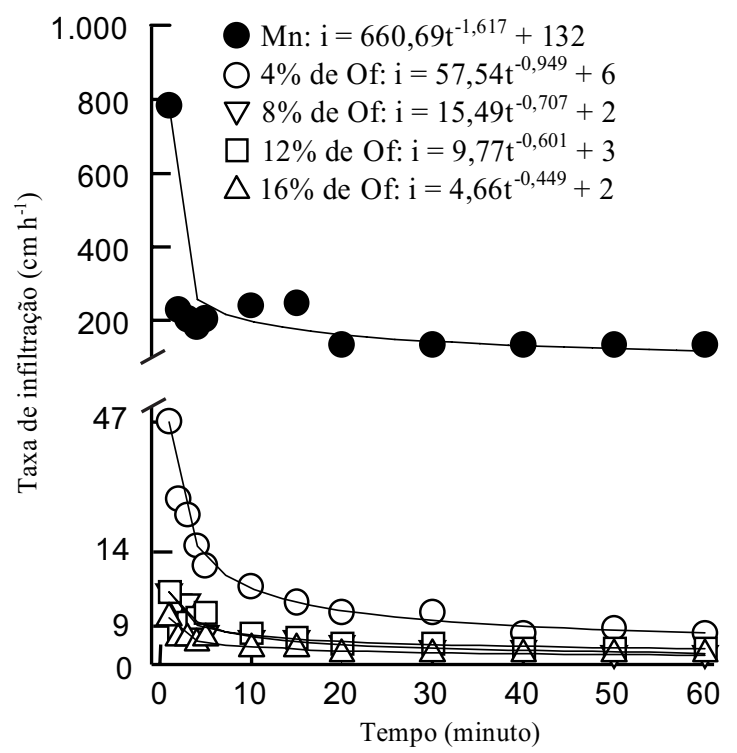

FIG. 3. Taxa de infiltração de água (i) em Cambissolo álico submetido a diferentes níveis de oferta de forragem (OF) com capim-elefante-anão cv. Mott e mata nativa (Mn). de infiltração ao final de uma hora de teste (Fig. 3), o que demonstra baixa capacidade de transmissão de água pelo solo. Isto pode ser atribuído à obstrução da porosidade, a qual já era baixa antes do teste de infiltração (Tabela 1 e Fig. 2), pelos sedimentos transportados pela água para dentro dos poros, desagregados em conseqüência do pisoteio animal. Contribuiu para isso o aumento da umidade do solo pelo efeito do alagamento ao longo do teste de infiltração. Ao final de uma hora de teste, todos os tratamentos de oferta de forragem estudados apresentaram praticamente a mesma taxa de infiltração de água, com exceção do tratamento com 4,0\%. Isto confirma que a taxa de infiltração de água em solo alagado é um processo que depende principalmente do tipo de solo (Baver et al., 1972), e sofre pouca influência do manejo. No tratamento $4,0 \%$ de oferta de forragem, o pisoteio dos animais foi distribuído uniformemente sobre toda a área pastejada, sem a formação de caminhos preferenciais pelos animais, distintamente do que ocorreu nos demais tratamentos, nos quais a sobra de forragem ao longo do período de condução do experimento permitiu o entouceiramento da cultura, com conseqüente formação de trilhas de caminhamento. Esta melhor distribuição da carga animal, no tratamento $4,0 \%$ de oferta de forragem, causou uma menor pressão média dos animais sobre o solo, com conseqüente menor volume de solo desagregado e disponível para o transporte para dentro dos poros do solo pela ação da água de infiltração, permitindo maior taxa de infiltração de água do que nos demais tratamentos. Além disso, deve ser considerado o fato de que um maior número de animais no tratamento $4,0 \%$ de oferta de forragem talvez tenha proporcionado o retorno de maior volume de dejetos sobre a superfície do solo, os quais podem ter contribuído para uma melhor estruturação do solo, já que a macroporosidade também foi ligeiramente mais alta do que no tratamento $8,0 \%$ de oferta de forragem (Tabela 1).

Chama-se a atenção, ainda, para a alta taxa de infiltração no tratamento-testemunha (mata nativa), explicada principalmente pela elevada porcentagem de macroporos em ambas as profundidades estudadas (Tabela 1 e Fig. 2), em relação aos demais tratamentos. 


\section{CONCLUSÕES}

1. O aumento na oferta de forragem afeta as propriedades físicas do solo, principalmente na profundidade de 0-5 cm; pode-se estabelecer o nível crítico de 12,0\% como limite inferior de oferta de forragem e, conseqüentemente, o limite superior de pressão de pastejo.

2. A densidade do solo diminui com o aumento da oferta de forragem, principalmente na profundidade $0-5 \mathrm{~cm}$.

3. O diâmetro médio ponderado de agregados, a macroporosidade e a porosidade total do solo aumentam com o aumento da oferta de forragem, principalmente na profundidade de $0-5 \mathrm{~cm}$.

4. A taxa inicial de infiltração de água no solo diminui com o aumento da oferta de forragem.

\section{REFERÊNCIAS}

ALDERFER, R.B.; ROBINSON, R.R. Runoff from pastures in relation to grazing intensity and soil compaction. Agronomy Journal, Madison, v.39, p.948-958, 1947.

BAVEL, C.H.M. van. Mean weight-diameter of soil aggregates as a statistical index of aggregation. Soil Science Society of America. Proceedings, Madison, v.38, p.826-830, 1949.

BAVER, L.D.; GARDNER, W.H.; GARDNER, W.R. Soil structure: evaluation and agricultural significance. In: BAVER, L.D.; GARDNER, W.H.; GARDNER, W.R. Soil physics. 4.ed. New York : J. Wiley, 1972. p.178-223.

BERTOL, I. Degradação física do solo sob a cultura do alho. Revista Agropecuária Catarinense, Florianópolis, v.2, n.2, p.47-50, 1989.

BERTOL, I.; GOMES, K.E.; DENARDIN, R.B.N.; ZAGO, L.A.; MARASCHIN, G.E. Propriedades físicas do solo relacionadas a diferentes níveis de oferta de forragem numa pastagem natural. Pesquisa Agropecuária Brasileira, Brasília, v.33, n.5, p.779786, maio 1998
BERTOL, I.; SANTOS, J.C.P. Uso do solo e propriedades físico-hídricas no Planalto Catarinense. Pesquisa Agropecuária Brasileira, Brasília, v.30, n.2, p.263-267, fev. 1995.

BLACK, C.A. Methods of soil analysis: chemical and microbiological properties. Madison : American Society of Agronomy, 1965. 1159p.

CHANCELLOR, W.J.; SCHMIDT, R.H.; SOEHNE, W. Laboratory measurement of soil compaction and plastic flow. Transactions of the ASAE, Saint Joseph, v.5, p.235-239, 1962.

FEDERER, C.A.; TENPAS, G.H.; SCHMITD, D.R.; TANNER, C.B. Pasture soil compaction by animal traffic. Agronomy Journal, Madison, v.53, p.53-54, 1961.

FORSYTHE, W. Física de suelos: manual de laboratório New York : University Press, 1975. 324p.

GRADWELL, M.W. Changes in the pore-space of a pasture topsoil under animal treading. New Zealand Journal of Agricultural Research, Wellington, v.4, p.663-674, 1960.

GRADWELL, M.W. Soil moisture deficiencies in puddled pastures. New Zealand Journal of Agricultural Research, Wellington, v.9, p.127-136, 1966.

PHILIP, J.R. The theory of infiltration. IV. Sorptivity and algebraic infiltration equations. Soil Science, Baltimore, v.84, p.257-264, 1957.

TAYLOR, H.M. Managing root systems to reduce plant water deficits. In: MEHTA, Y.R. The soil-root system in relation to Brazilian agriculture. Londrina : IAPAR, 1981. p.45-60.

TISDALL, J.M.; COCKROFT, B.; UREN, N.C. The stability of soil aggregates as affected by organic materials, microbial activity and physical disruption. Australian Journal of Soil Research, Melbourne, v.16, p.9-17, 1978.

UNIVERSIDADE FEDERAL DE SANTA MARIA. Levantamento de reconhecimento dos solos do Estado de Santa Catarina. Santa Maria : UFSM SUDESUL, 1973. 2v. 